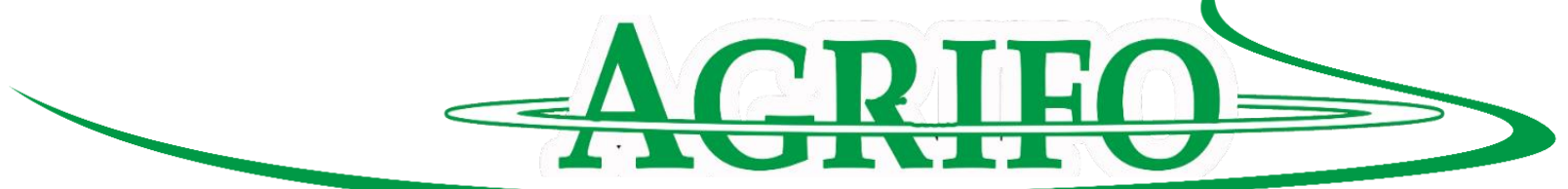

\title{
PENGARUH TINGKAT IMITASI DAN KOSMOPOLITAN WANITA TANI TERHADAP KEPUTUSAN PENGELOLAAN USAHATANI
}

\section{Anita Suharyani ${ }^{1}$, Shenny Oktoriana ${ }^{1}$}

Corresponding Author : anita.suharyani@faperta.untan.ac.id

\begin{abstract}
The aims of this study are to analyze cosmopolitan and imitation levels of women farmers, and the influence of cosmopolitan and imitation levels of women farmers towards decision of farming management. This study was conducted in Limbung Village, Kubu Raya District, West Kalimantan. Respondent in this study consist of 26 womens who joint in women farmers group and 38 womens who do not joint in women farmers group. The method that used in this study are descriptive analyze and corelation analyze. The results showed that imitation level of women farmers group women farmers group is in average level. Beside that, the cosmopolitan level of women farmers group women farmers group is in high level. The result also showed that there is corelation between imitation and cosmopolitan levels has significant influence in decision of management farming.
\end{abstract}

Keywords: Imitation, Cosmopolitan, Women Farmers

\section{PENDAHULUAN}

Usahatani merupakan kegiatan yang mengalokasikan sumberdaya yang ada secara efektif dan efisien dengan tujuan untuk memperoleh keuntungan yang sebesar-besarnya selama periode waktu tertentu (Soekartawi, 2002). Petani dalam melakukan usahatani memilik peran salah satunya adalah sebagai manajer dimana mereka mengatur segala kegiatan di dalamnya agar mencapai tujuan yang diharapkan.

Dewasa ini, wanita tani tidak hanya memiliki peran tradisional yang mengurus segala keperluan rumah tangga. Mereka juga ikut berperan dalam mencari nafkah dengan membantu suaminya dalam berusahatani. Wanita tani berperan dalam perencanaan, pengambilan keputusan dan pelaksanaan usahatani baik on farm maupun off farm. Sehingga tidak jarang, wanita tani mampu memberikan informasi yang lebih mengenai usahatani.
Informasi yang diperoleh oleh wanita tani dipengaruhi oleh beberapa faktor, antara lain tingkat imitasi dan kosmopolitan. Imitasi adalah suatu tindakan meniru orang lain, yang bisa dilakukan dalam bermacam-macam bentuk. Misalnya, gaya bicara, tingkah laku, adat dan kebiasaan, pola pikir, serta apa saja yang dimiliki atau dilakukan oleh seseorang (Huki, 2016). Imitasi menjadi salah satu faktor penentu terjadinya interaksi sosial. Hal ini senada dengan hasil penelitian Witrianto (2009), interaksi sosial antara petani dan bukan petani (sebagai pendatang) di Kabupaten Solok Sumatera Barat, menunjukkan bahwa salah satu faktor yang mendorong interaksi tersebut adalah imitasi, yaitu dalam hal-hal pola hidup. Petani meniru pola hidup penduduk yang bukan petani dalam hal mengatur keuangan, cara berpakaian dan penampilan.

Kosmopolitan merupakan sikap keterbukaan pandangan seseorang yang dapat dilihat dari karakteristik yang mempunyai hubungan dan pandangan

\footnotetext{
${ }^{1}$ Staff Pengajar Fakultas Pertanian Universitas Tanjungpura
} 
yang luas dengan dunia luar maupun kelompok lainnya dan memiliki mobilitas yang tinggi (Mardikanto \& Sutarni, 1982). Kosmopolitan biasanya dicirikan dengan frekuansi pergi ke kota atau keluar kota kabupaten dan jarak perjalanan yang dilakukan, serta pemanfaatan media massa. Hasil penelitian yang dilakukan oleh Khasanah (2008) menunjukkan bahwa kosmopolitan memiliki hubungan sangat signifikan terhadap adopsi inovasi teknologi budidaya tanaman jarak pagar. Semakin tinggi tingkat kekosmopolitannya maka akan semakin tinggi tingkat penerapan teknologinya, semakin sering responden dalam mencari informasi yang berkaitan dengan kegiatan usahatani dan berpengaruh besar dalam penerapan teknologi pada usahataninya.

Keterlibatan wanita dalam usahatani menyebabkan munculnya kelompok-kelompok wanita tani, dimana merupakan salah satu hasil dari adanya proses sosial yang terjadi di pedesaan. Meskipun demikian, masih banyak dijumpai wanita tani yang tidak bergabung dalam kelompok. Keduanya bisa saja memiliki perbedaan cara pandang mengenai pengelolaan usahatani yang dilakukan karena pada dasarnya seseorang yang lebih banyak berinteraksi dengan orang lain memiliki wawasan yang lebih luas.

Oleh karena itu, perlu adanya kajian mengenai tingkat imitasi dan kosmopolitan wanita tani terhadap keputusan pengelolaan usahatani baik yang bergabung dalam kelompok wanita tani maupun yang tidak bergabung dalam kelompok wanita tani. Berdasarkan hal tersebut tujuan dari penelitian ini adalah untuk mengetahui tingkat imitasi dan kosmopolitan wanita tani serta mengetahui pengaruh tingkat imitasi dan kosmopolitan wanita tani terhadap keputusan pengelolaan usahatani.

\section{METODE PENELITIAN}

Penelitian ini di Dusun Sidorejo dan Mulyorejo, Desa Limbung, Kecamatan Sungai Raya, Kabupaten Kubu Raya yang dilaksanakan pada tahun 2017. Pemilihan kedua Dusun tersebut dikarenakan keduanya merupakan dusun dengan jumlah wanita tani yang paling banyak berusahatani.

Pengambilan sample dilakukan dengan metode stratified sampling dengan teknik snowball sampling. Jumlah sample yang digunakan dalam penelitian ini sebanyak 64 orang wanita tani, yang terdiri dari satu kelompok wanita tani (KT) "Usaha Karya Tani" sebanyak 26 orang dan 38 orang yang tidak tergabung dalam kelompok wanita tani (NKT).

Pengukuran tingkat imitasi wanita tani difokuskan pada pengaruh lingkungan sekitar terhadap keputusan responden dalam pengelolaan usahataninya. Tingkat imitasi responden dilihat berdasarkan tujuh indikator, yaitu: 1) keputusan pemilihan jenis komoditi yang ditanam; 2) keputusan waktu tanam; 3) keputusan cara persiapan lahan; 4) keputusan cara perawatan tanaman; 5) keputusan aplikasi pupuk dan pestisida; 6) keputusan pengolahan pasca panen; dan 7) keputusan pemasaran hasil.

Pengukuran tingkat kosmopolitan wanita tani dilakukan untuk melihat sikap keterbukaan responden terhadap informasi dan perkembangan di lingkungan luar desanya. Indikatornya terdiri dari: 1) koneksi di luar desa; 2) frekuensi keluar desa dalam satu tahun; 3) jarak tempuh perjalanan keluar desa; dan 4) pemanfaatan media masa dalam sebulan. 
Indikator-indikator pada tingkat imitasi dan kosmopolitan diberi skor 1-3, dimana ditentukan dengan metode central tendency berdasarkan hasil data yang telah terkumpul.

\section{HASIL DAN PEMBAHASAN}

Hasil pengukuran tingkat imitasi wanita tani berdasarkan tujuh indikator, menunjukan bahwa secara keseluruhan tingkat imitasi wanita tani didominasi tingkat sedang untuk responden yang tergabung dalam kelompok tani (KT), dan tergolong tinggi untuk wanita tani yang tidak tergabung dalam kelompok tani (NKT). Hasil pengukuran indikator tingkat imitasi sebagai berikut.

Tabel 1. Tingkat Imitasi Wanita Tani dalam Kelompok Tani (KT)

\begin{tabular}{llrrr}
\hline \multirow{2}{*}{ No } & Indikator & \multicolumn{3}{c}{ Tingkat Imitasi (\%) } \\
\cline { 3 - 5 } & & $\mathrm{T}$ & $\mathrm{S}$ & $\mathrm{R}$ \\
\hline 1 & Pemilihan jenis komoditi & 88.46 & 7.67 & 3.85 \\
2 & Waktu tanam & 92.31 & 3.85 & 3.85 \\
3 & Persiapan lahan & 3.85 & 92.31 & 3.85 \\
4 & Perawatan tanaman & 15.38 & 84.62 & 0.00 \\
5 & Aplikasi pupuk dan pestisida & 11.54 & 0.00 & 88.64 \\
6 & Pengolahan pasca panen & 11.54 & 88.46 & 0.00 \\
7 & Pemasaran hasil & 3.85 & 96.15 & 0.00 \\
\hline & Rata-rata & 32.42 & 53.29 & 14.31 \\
\hline
\end{tabular}

Sumber : Data primer diolah (2017)

Keterangan : $\mathrm{T}=$ Tinggi, $\mathrm{S}=$ Sedang, $\mathrm{R}=$ Rendah

Tingkat imitasi wanita tani dalam kelompok (KT) tergolong sedang dikarenakan beberapa faktor antara lain:

1. Penentuan komoditi yang akan ditanam merupakan keputusan bersama dalam kelompok tani sehingga jenis komoditi yang ditanam cenderung seragam.

2. Keputusan waktu tanam cenderung seragam karena keseragaman jenis komoditi yang ditanam.

3. Persiapan lahan tidak diatur dalam kelompok sehingga masing-masing anggota kelompok mengolah lahan berdasarkan kebiasaan atau tergantung dari kondisi lahannya.

4. Perawatan tanaman bedasarkan kebiasaan yang dikombinasikan dengan pengetahuan yang diperoleh dari penyuluh maupun petani lain.

5. Pengaplikasian pupuk dan pestisida, pengolahan lahan pasca panen, serta pemasaran hasil panen dilakukan berdasarkan kebiasaan responden. Responden beranggapan bahwa kebiasaan yang telah dilakukan sudah baik sehingga memudahkan responden dalam berusahatani. 
Tabel 2. Tingkat Imitasi Wanita Tani Non Kelompok Tani (NKT)

\begin{tabular}{llrrr}
\hline \multirow{2}{*}{ No } & Indikator & \multicolumn{3}{c}{ Tingkat Imitasi (\%) } \\
\cline { 3 - 5 } & & $\mathrm{T}$ & $\mathrm{S}$ & $\mathrm{R}$ \\
\hline 1 & Pemilihan jenis komoditi & 57.89 & 2.63 & 39.47 \\
2 & Waktu tanam & 60.53 & 0 & 39.47 \\
3 & Persiapan lahan & 55.26 & 5.26 & 39.47 \\
4 & Perawatan tanaman & 21.05 & 78.95 & 0 \\
5 & Aplikasi pupuk dan pestisida & 31.58 & 0.00 & 68.42 \\
6 & Pengolahan pasca panen & 13.16 & 86.84 & 0.00 \\
7 & Pemasaran hasil & 31.58 & 68.42 & 0.00 \\
\hline & Rata-rata & 38.72 & 34.59 & 26.69 \\
\hline
\end{tabular}

Sumber : Data primer diolah (2017)

Keterangan : $\mathrm{T}=$ Tinggi, $\mathrm{S}=$ Sedang, $\mathrm{R}=$ Rendah

Tingkat kosmopolitan wanita tani non kelompok (NKT) tergolong tinggi. Pengetahuan yang didapatkan responden NKT lebih sedikit daripada responden KT sehingga ada kecenderungan petani NKT lebih banyak mengikuti petani lain tanpa mengetahui pengetahuan tersebut secara lebih mendalam sehingga penerapan pengelolaan usahatani yang dilakukan berdasarkan yang nampak pada petani yang menjadi acuannya. Misalnya pada pengolahan lahan, responden banyak yang mengikuti cara petani lain yang lokasi lahannya bersebelahan dengan lahan milik responden tanpa mengetahui teknik pengolahan lahan secara lebih mendalam.

Hasil pengukuran tingkat kosmopolitan berdasarkan keempat indikator menunjukan bahwa secara keseluruhan tingkat kosmopolitan wanita tani baik dalam kelompok (KT) maupun non kelompok (NKT) tergolong tinggi. Pengukuran tingkat kosmopolitan berdasarkan indikator sebagai berikut.

Tabel 3. Tingkat Kosmopolitan Wanita Tani dalam Kelompok Tani (KT)

\begin{tabular}{llrrr}
\hline \multirow{2}{*}{ No } & Indikator & \multicolumn{3}{c}{ Tingkat Imitasi (\%) } \\
\cline { 3 - 5 } & & $\mathrm{T}$ & $\mathrm{S}$ & $\mathrm{R}$ \\
\hline 1 & Koneksi di luar desa & 26.92 & 42.31 & 30.77 \\
2 & Frekuensi keluar desa & 30.77 & 7.69 & 61.54 \\
3 & Jarak tempuh perjalanan keluar desa & 50.00 & 26.92 & 23.08 \\
4 & Pemanfaatan media masa & 61.54 & 0.00 & 38.46 \\
\hline & Rata-rata & 42.31 & 19.23 & 38.46 \\
\hline
\end{tabular}

Sumber : Data primer diolah (2017)

Keterangan : $\mathrm{T}=$ Tinggi, $\mathrm{S}=$ Sedang, $\mathrm{R}=$ Rendah 
Tabel 4. Tingkat Kosmopolitan Wanita Tani Non Kelompok Tani (NKT)

\begin{tabular}{llrrr}
\hline \multirow{2}{*}{ No } & Indikator & \multicolumn{3}{c}{ Tingkat Imitasi (\%) } \\
\cline { 3 - 5 } & & $\mathrm{T}$ & $\mathrm{S}$ & $\mathrm{R}$ \\
\hline 1 & Koneksi di luar desa & 39.47 & 42.11 & 18.42 \\
2 & Frekuensi keluar desa & 21.05 & 5.26 & 73.68 \\
3 & Jarak tempuh perjalanan keluar desa & 44.74 & 34.21 & 21.05 \\
4 & Pemanfaatan media masa & 84.21 & 0.00 & 15.79 \\
\hline & Rata-rata & 47.37 & 20.40 & 32.24 \\
\hline
\end{tabular}

Sumber : Data primer diolah (2017)

Keterangan : $\mathrm{T}=$ Tinggi, $\mathrm{S}=$ Sedang, $\mathrm{R}=$ Rendah

Memiliki kenalan atau koneksi di luar desa menunjukkan adanya hubungan antara petani dengan lingkungan di luar desa. Semakin besar responden melakukan koneksi dengan pihak luar desa, maka semakin tinggi peluangnya untuk memiliki keterbukaan sikap dan keluasan wawasan yang dimilikinya, yang menjadi gambaran kosmopolitan.

Kedua kelompok responden menunjukkan dominasi tingkat kosmopolitan berdasarkan koneksi di luar desa yang sama, yaitu pada tingkat sedang. Koneksi responden di luar desa biasanya merupakan keluarga, tengkulak ataupun pedagang dari luar desa, penjual bibit maupun peralatan pertanian, dan petani yang pernah melakukan kegiatan bersam.

Frekuensi keluar desa menggambarkan intensitas wanita tani dalam berinteraksi dengan lingkungan luar desa. Frekuensi keluar desa diukur berdasarkan jumlah kegiatan keluar desa yang dilakukan oleh wanita tani untuk beberapa tujuan, antara lain mengunjungi saudara, mengikuti pelatihan, membeli kebutuhan rumah tangga, memenuhi kebutuhan usahatani, mencari informasi harga komoditi, serta memenuhi undangan.

$\begin{array}{crr}\text { Hasil } & \text { penelitian } & \text { penelitian } \\ \text { menunjukkan } & \text { bahwa } & \text { tingkat }\end{array}$

kosmopolitan dilihat dari frekuensi keluar desa untuk kedua kelompok responden menunjukkan kecenderungan yang sama, yaitu pada tingkat rendah. Namun sebagian jika dilihat lebih rinci, responden KT memiliki tingkat kosmopolitan yang lebih tinggi daripada responden NKT. Hal ini disebabkan responden KT memiliki usaha sampingan seperti membuka toko kelontong sehingga mereka lebih banyak keluar desa untuk membeli barangbarang kebutuhan tokonya.

Tingkat kosmopolitan wanita tani dilihat dari jarak tempuh perjalanan keluar desa menunjukkan kecenderungan yang yaitu pada tingkat kosmopolitan tinggi. Akan tetapi, tingkat kosmopolitan responden KT lebih tinggi daripada responden NKT. Perbedaan ini dikarenakan responden KT lebih banyak melakukan perjalanan ke luar desa seperti berbelanja kebutuhan toko.

Pemanfaatan media massa menggambarkan kepedulian petani terhadap isu-isu perkembangan di lingkungan luar desa. Hal tersebut juga sebagai gambara tingkat wawasan yang dimiliki oleh wanita tani. Hasil penelitian menunjukan bahwa kedua kelompok responden tergolong dalam tingkat kosmopolitan tinggi.

Tingginya tingkat kosmopolitan bersasarkan pemanfaatan media masa 
mengindikasikan bahwa responden sudah terbuka dengan dunia luar. Akses terhadap media massa yang paling tinggi yaitu dalam pemanfaatan televisi. Wanita tani memanfaatkan televisi untuk mendapatkan infomasi dan berita terbaru, serta untuk hiburan keluarga.
Pengaruh tingkat imitasi dan kosmopolitan terhadap keputusan pengelolaan usahatani dilakukan untuk menganalisis korelasi keduanya. Hasil uji beda ditunjukan pada tabel berikut.

Tabel 5. Uji Korelasi Tingkat Imitasi dan Kosmopolitan Wanita Tani Terhadap Keputusan Pengelolaan Usahatani

\begin{tabular}{lrrrrr}
\hline \multirow{2}{*}{ model } & \multicolumn{2}{c}{ Unstandardized Coeff. } & \multicolumn{1}{c}{ Std. Coef. } & \multicolumn{1}{c}{ t } & \multicolumn{1}{c}{ Sig. } \\
\cline { 2 - 6 } & \multicolumn{1}{c}{ B } & \multicolumn{1}{c}{ Std. Error } & \multicolumn{1}{c}{ Beta } & & \\
\hline 1 (constant) & 144.684 & 15.822 & & 9.144 & .000 \\
Imitasi & -.175 & .096 & -.222 & -1.813 & .075 \\
Kosmo & .103 & .034 & .377 & 3.083 & .003 \\
\hline
\end{tabular}

Sumber : Data primer diolah (2017)

Hasil analisis menunjukkan bahwa terdapat korelasi yang signifikan antara tingkat imitasi dan kosmopolitan terhadap keputusan pengelolaan usahatani yang dilakukan oleh wanita tani.

Nilai koefisien imitasi yang bernilai negatif berarti bahwa semakin rendah tingkat imitasi wanita tani maka semakin tinggi perannya dalam pengambilan keputusan usahatani. Sebaliknya jika tingkat imitasi semakin tinggi, maka peran wanita tani dalam pengambilan keputusan usahatani semakin rendah.

Nilai koefisien kosmopolitan yang bernilai positif menunjukkan bahwa semakin rendah tingkat kosmopolitan wanita tani maka semakin rendah juga perannya dalam pengambilan keputusan usahatani. Sebaliknya jika tingkat kosmopolitan semakin tinggi, maka peran wanita tani dalam pengambilan keputusan usahatani juga semakin tinggi. artinya wanita tani yang memiliki wawasan luas akan memiliki pengaruh yang lebih besar terhadap segala keputusan yang dibuat dalam menjalankan usahataninya.

\section{KESIMPULAN} adalah:

Kesimpulan dari penelitian ini

1. Tingkat imitasi wanita tani didominasi tingkat sedang untuk responden yang tergabung dalam kelompok tani (KT), dan tergolong tinggi untuk wanita tani yang tidak tergabung dalam kelompok tani (NKT).

2. Tingkat kosmopolitan wanita tani baik dalam kelompok (KT) maupun non kelompok (NKT) tergolong tinggi.

3. Tingkat imitasi dan kosmopolitan responden berpengaruh signifikan terhadap keputusan pengelolaan usahatani yang dilakukan.

\section{DAFTAR PUSTAKA}

Endang, Rini, IM. Narka Tenaya dan NW Sri Astiti. 2014. Peran Wanita Tani dalam Penerapan Teknologi Pengelolaan Tanaman Terpadi (PTT) pada Usahatani Jagung di Kecamatan Pringgabaya Kabupaten Lombok Timur. Jurnal Manajemen Agribisnis Vol 2 No.1: 76-83. 
Huki, L. 2016. Pengertian imitasi dan sugesti. Diambil kembali dari Blog Pengetahuan: http://anen9.blogspot.co.id/2016/ 03/pengertian-imitasi-dansugesti.html

Khasanah, W. 2008. Hubungan FaktorFaktor Sosial Ekonomi Petani dengan Tingkat Adopsi Inovasi Teknologi Budidaya Tanaman Jarak Pagar (Jatropha curcas L.) di Kecamatan Lendah Kabupaten Kulon Progo. Surakarta: Faklutas Pertanian Universitas Sebelas Maret.

Mardikanto, T., \& Sutarni, S. 1982. Penyuluhan Pembangunan Pertanian dalam Teori dan Praktek. Jakarta: Hapsari.
Soekartawi. 2002. Analisis Usahatani. Jakarta: UI Press.

Soekanto, S. 2015. Sosiologi Suatu Pengantar. Jakarta: PT. RajaGrafindo Persada.

Tim Survey Sosial Ekonomi. (2015). Final Report of Fifth Year's Baseline Survey of The Project for Program of Community Development of Fire Control in Peat Land Area. Pontianak: Fakultas Pertanian Universitas Tanjungpura-Japan International Cooperation Agency (JICA).

Witrianto. 2009. Interaksi Sosial Antara Petani dan Bukan Petani di Nagari Selayo Kabupaten Solok Sumatera Barat. 